Folia Histórica del Nordeste, $\mathbf{N}^{\mathbf{0}} 21$ (Resistencia, 2013) IIGHI, IH - CONICET, UNNE

\title{
EL FOGÓN DE LOS ARRIEROS ¿UNA VANGUARDIA DESPOLITIZADA? ALGUNAS CONSIDERACIONES ACERCA DE LA MODERNIDAD ARTISTICA EN RESISTENCIA (1940-1960)
}

\author{
El Fogón de los Arrieros. A depoliticized avant-garde? Some considerations \\ on the artistic modernity in Resistencia (1940-1960)
}

\begin{abstract}
Alejandra Reyero
\section{Resumen}

El trabajo explora el contexto cultural de la provincia de Chaco en el marco de la modernidad artística argentina. Toma como punto de referencia a la capital provincial (Resistencia) y analiza, desde una perspectiva sociológica, el rol de El Fogón de los Arrieros. Institución que -entre los años 1940 y 1960 - marcó un quiebre en la historia cultural de la ciudad; y actuó de manera decisiva en la consolidación de un campo artístico regional. El objetivo particular es comenzar a reflexionar sobre la relación artepolítica en Resistencia (aspecto prácticamente inexplorado por la historiografía local) y abrir el debate sobre la existencia de expresiones propiamente vanguardistas en ciudades periféricas de la Argentina.
\end{abstract}

$<$ modernidad $><$ arte $><$ política $><$ Chaco $><$ Argentina $>$

\begin{abstract}
This paper concerns the cultural context of the Chaco state within the framework of the Argentinean artistic modernity. It takes the Chaco capital (Resistencia) as reference point and it analyzes, from a sociological perspective, the role of the institution named El Fogón de los Arrieros. Between 1940 and 1960, this institution was a turning point for the cultural history of Resistencia and the consolidation of a regional artistic field. The specific purpose of this paper is to reflect on the art-politics relation in Resistencia (a practically unexplored matter in the local historiography), and open a debate on the existence of strictly avant-garde expressions in outlying Argentinean cities.
\end{abstract}

$$
<\text { modernity }><\text { art }><\text { politics }><\text { Chaco }><\text { Argentina }>
$$


Deslizar una mirada socio-histórica al arte visual chaqueño del siglo XX, supone emprender un recorrido por el continuo y diverso aporte de diversas figuras y personalidades, que pertenecientes al ámbito de la pintura, la escultura, el grabado, la fotografía y el teatro, han sabido sentar las bases para la conformación y reafirmación de una identidad artística local. Pero también -paralelamente- implica anclar esta producción en el desarrollo cultural e institucional de la provincia de Chaco y a su vez en el desarrollo de la modernidad artística argentina. Desarrollo atravesado por importantes periodos de crisis, dentro de los cuales tiene lugar una compleja variedad de expresiones que conjugadas con eventos socioculturales específicos, estimulan la convergencia de personas en determinados núcleos o agrupamientos.

En el caso chaqueño, numerosas fueron las articulaciones entre artistas y organismos oficiales y privados que atentas a diversos fines suscitaron la aparición de nuevos espacios para la gestación de iniciativas categóricas en la concreción de acciones culturales.

El presente trabajo propone abordar la producción cultural de la provincia de Chaco durante las décadas que van de 1940 a 1960, enmarcando tal recorte dentro de la problemática de la modernidad artística argentina. Analizar desde una perspectiva sociológica del arte, los procesos históricos regionales que comprende el arte chaqueño en este lapso, tomando como punto de referencia a la capital provincial (Resistencia) y a una de las formaciones culturales que allí se conformó. Contribuir de esta manera y a partir de la lectura del accionar de esta formación, a una comprensión "más abarcadora" del arte regional.

Para ello nos detendremos en una de las expresiones de las relaciones sociales efectivizadas a partir de la cultura moderna: las experiencias de grupo o proyectos de actores sociales articulados con objetivos comunes de cambio cultural y estrategias precisas de renovación estética. En el caso que nos ocupa, surge en Resistencia, en la década del '40 un nucleamiento cuya peculiaridad marcó un quiebre en la historia cultural de la ciudad otorgando vital impulso al accionar artístico chaqueño y actuando - de manera sino decisiva al menos relevante- en la consolidación de un campo artístico regional: El Fogón de los Arrieros.

No es el objetivo de este trabajo analizar sistemáticamente ésta y otras formaciones culturales que la antecedieron y sucedieron-formaciones cuya complejidad y peculiaridad demandarían una estudio aparte- sino trazar un recorrido histórico por los diferentes contextos en los cuales dicha formación tuvo lugar, examinado los motivos e intereses que llevaron a sus integrantes a vincularse entre sí y con los demás artistas y sujetos sociales de la época. Este análisis, atento a la organización interna de esta formación y a su participación en la conformación, dinámica y funcionamiento del campo artístico resistenciano en el contexto de la modernidad argentina, quizás nos permita comprender las disonancias y afinidades con las manifestaciones culturales producidas en otros puntos del país. Muchas de las circunstancias sociales, políticas y artísticas atravesadas por la Argentina entre 1940 y 1960, devienen un marco necesario 
al momento de pensar la situación del arte chaqueño. Circunstancias en las que no sólo cambian las formas de expresión, sino también las formas de comunicación y percepción de la praxis artística. Nos interesa entonces -tomando una expresión de Andreas Huyssen (2005:235) - percibir retrospectivamente la modernidad artística en Resistencia, analizar cuáles fueron los valores y conocimientos que vehiculizó y cómo funcionó culturalmente a lo largo de dos décadas.

El objetivo particular, que da el título a la propuesta, es comenzar a reflexionar sobre la relación arte-política en Resistencia (aspecto prácticamente inexplorado por la historiografía local) y abrir el debate sobre la existencia de expresiones propiamente vanguardistas en la Resistencia de esta época.

La primera parte del trabajo gira en torno a la historia y estado del campo cultural chaqueño de la primera mitad del siglo XX y analiza el accionar de El Fogón de los Arrieros y su intervención en la modernidad de Resistencia.

Los años '60 en Resistencia y su relación con el resto del país será el foco de atención de la segunda parte del trabajo, en el que se reflexiona especialmente sobre el vínculo arte-política.

El trabajo en su totalidad se apoyará en la noción de modernidad como eje vertebral. La misma será entendida no sólo como "espíritu de época”, sino también y especialmente como aquel "mundo de representaciones" que en términos de Casullo (2005: 21) refundó valores, saberes y certezas. Estableció paradigmas para la acción y la reflexión, para la crítica y la utopía. Fijó identidades para la multiplicidad de lo real, denominadores comunes para el acceso al conocimiento y códigos -según nuestra mirada- de "presumible" alcance universal para la interiorización de los fenómenos.

Pese a esta taxativa definición, existen -en los campos de las ciencias sociales y la filosofía actual- múltiples dimensiones, acepciones y cronologías atribuidas desde diversos enfoques a la noción de modernidad. En las páginas que siguen intentaremos pensarla desde un punto de vista "integral". Esto es, interpretarla paralelamente como época o experiencia histórica ${ }^{1}$. Experiencia atravesada por un proceso de importantes fluctuaciones y transformaciones socioeconómicas, tecnocientíficas e industriales (proceso conocido como “modernización”) y vivida y valorada culturalmente, en nuestro caso por la sociedad chaqueña. La visión cultural que determinado grupo social (en nuestro caso el nucleado alrededor de El Fogón de los Arrieros) tiene de la modernidad y que se materializa en un "proyecto cultural", discurso o conjunto de valores y

\footnotetext{
${ }^{1}$ Mientras que para algunos autores la Modernidad se inscribe entre fines del siglo XVIII, con el inicio de la Revolución Industrial y el siglo XX; otros como Marshall Berman consideran que el primer hombre moderno se gesta ya en el Renacimiento (Anderson, 2005). Este es un tema sumamente discutido y presenta distintas variantes en cuanto a su cronología y acepción cultural, política y social. Por tal razón este trabajo no entrará en dicho terreno limitándose a resaltar los aspectos de la modernidad que interesan a los fines del análisis del caso de estudio.
} 
representaciones acerca de la modernidad. Nos referimos a aquellos movimientos artísticos e intelectuales que tuvieron lugar durante el siglo XX en Resistencia ${ }^{2}$.

Para examinar los motivos e intereses que llevaron a los integrantes de $E l$ Fogón de los Arrieros a vincularse entre sí y con los demás artistas y sujetos sociales de la época, es preciso entender la noción de formación cultural como movimiento y/o tendencia efectiva en la vida intelectual y artística de Resistencia hacia mediados de los años '40. Movimiento que tiene influencia significativa y a veces decisiva sobre el desarrollo activo de dicha cultura y que presenta una relación variable y a veces solapada con las "instituciones formales" (Williams, 2000:139). Ello implica atender no sólo a la organización interna de esta formación sino también a su participación en la conformación, dinámica y funcionamiento del campo artístico resistenciano en el contexto de la modernidad argentina.

\section{1. "Cosas serias con aire risueño": El Fogón de los Arrieros}

Una de las primeras formaciones culturales de la década del ' 40 que ha tenido una importante intervención en el campo cultural de la ciudad de Resistencia, fue $E l$ Fogón de los Arrieros. Analizar el accionar de esta agrupación durante el periodo comprendido entre los años 1940 y 1960 supone, como dijimos, considerar sus condiciones sociales, las relaciones culturales que se generan en y a partir de la misma, como así también los medios y materiales de tales relaciones culturales.

El planteamiento de algunos interrogantes sociológicos y las nuevas y posibles respuestas sugeridas a partir del análisis formacional propuesto por Williams (1994:7879), entendido como el estudio de una formación (la modalidad de organización de productores culturales nucleados en torno a intereses comunes) a partir de la descripción y análisis del contexto histórico general, la consideración de las diferencias individuales al interior de la misma formación, en estrecha relación con las formas culturales concretas; nos permitirá ver cómo ciertos rasgos de la organización social y cultural de Resistencia entre los años '40, '50 y '60 cambiaron o se modificaron en el mismo momento en que se produjeron cambios artísticos específicos al interior de El Fogón de los Arrieros: ¿cuál es el tipo de función cultural, artística y social desempeñada por el Fogón en estos años y cuáles las relaciones que se produjeron al interior como al exterior del grupo? ¿Cuál fue su participación en las producciones culturales de la época y en años posteriores? ¿Cuáles fueron sus formas de identificación y asociación? ¿Su surgimiento fue una continuidad o una variación de las formas heredadas? ¿Si la respuesta es la segunda opción, ¿están-siguiendo a Williams- estas

\footnotetext{
${ }^{2}$ En términos de García Canclini (1995:31), la modernidad está vinculada a cuatro proyectos que tienen su origen en la Ilustración francesa y su consecuente revolución política: 1)- un proyecto emancipador que implica la secularización de las ciencias y el arte y su autonomía del poder (religioso o político); 2)- un proyecto expansivo (difusión del conocimiento y expansión del capital aplicados al desarrollo de la técnica y la industria); 3)- un proyecto renovador (constante innovación de las ciencias, las artes y los productos de consumo); 4)- un proyecto democratizador (difusión de los saberes para lograr una evolución racional y moral).
} 
variaciones íntimamente relacionadas con cambios en las relaciones sociales generales de la producción? Si se lo enmarca dentro de los grupos de ruptura ¿cuál es el tipo de disolución propuesta y cuál su tendencia artística? ¿Puede hablarse de un espíritu vanguardista-rupturista de sus integrantes respecto del arte tradicional? ¿Cuál fue su postura en los '60 en el plano político?

Esta nueva agrupación surge informalmente a mediados de los años 1943 y 1944, tras la iniciativa de los hermanos Aldo y Efraín Boglietti ${ }^{3}$ y Juan de Dios Mena, quienes se reunían en el hogar de los primeros a prolongar las entretenidas jornadas del Ateneo del Chaco ${ }^{4}$. Primero fueron sus propios amigos quienes se sumaron a estas tertulias culturales de los martes, gradualmente se fueron incorporando también las mismas personalidades que frecuentaban el Ateneo y posteriormente los amigos y conocidos de éstos. El interés por estas nuevas reuniones se incrementó a la par de las continuas presencias de los asiduos, al punto tal que "la casa de los Boglietti" se convirtió en el lugar habitual de artistas y "conocedores de cosas del espíritu", pasando a ser el taller literario de poetas y escritores, el escenario de grupos de teatro, la tribuna de disertantes preocupados por cuestiones artísticas y el atelier de pintores, escultores y tallistas conocido como "el cementerio" donde se hallan "los fogoneros" (Giordano, 1997:11) $)^{5}$

La propuesta inicial era convocar a los interesados a "hacer noche y no aquerenciarse". Tras prolongadas noches de profundos intercambios culturales (exposiciones de obras, charlas, conferencias, etc.) surgen -por una ocurrencia humorística de Mena- los seudónimos de "peón” y "capataz". El primero fue destinado a Aldo Boglietti, el segundo al mismo Mena, quien al poco tiempo de las sucesivas reuniones "se aquerencia" y pasa a vivir en el mismo edificio junto a Aldo Boglietti'. Años más tarde estos seudónimos se transforman en el eslogan de la agrupación y aparecen en la entrada del edificio como "aviso de presentación". A ellos se suman unos versos que invitan al transeúnte a entrar: "Si has de agregar una sonrisa al vino y a la sal que te ofrece nuestra casa, detén pasajero tu camino. Abre la puerta sin llamar y pasa."

Pasados algunos años de estas primeras reuniones, surge hacia 1949 el nombre de "El Fogón de los Arrieros". El mismo había sido propuesto por Mena y si bien

\footnotetext{
${ }^{3}$ Oriundos de Rosario, llegan a Resistencia en el periodo de mayor actividad del Ateneo del Chaco. Su profundo interés por el arte (ya en Rosario Aldo había participado de la cultura lírica desempeñándose como barítono) los lleva a vincularse con Alberto Torres, y los demás participantes de las tertulias del Ateneo. Desde entonces concurren con frecuencia a esta entidad, llegando Efraín a ser secretario de la misma (Giordano, 1997).

${ }^{4}$ Esta incipiente iniciativa grupal nace como la primera agrupación orgánica de Resistencia, o en términos de Williams, la primera "formación cultural" con una sólida estructura y conciencia de grupo, mediante la cual se concretaron intensas relaciones tanto al interior como al exterior de la agrupación.

${ }^{5}$ Entre ellos los plásticos Alfredo Pértile, Carlos Schenone, José Zali, René Brusau.

${ }^{6}$ Mientras Aldo Boglietti estaba profundamente interesado en la organización y promoción de actividades culturales y el apoyo a artistas locales, Mena estaba más abocado a la producción poética y escultórica, pero ambos sentían un profundo compromiso por la cultura chaqueña y pensaban que la amistad era el eje que permitía nuclear a artistas, entusiastas y público en general.
} 
puede intuirse en el mismo cierto dejo de ironía, también se advierte explícitamente la tendencia localista de Mena. Tendencia expresada en su misma obra poética y escultórica y en su propia figura conocida en el ambiente cultural como "el gaucho Mena". Desde otra lectura, el nombre parecería querer simbolizar también la reunión de amigos alrededor de su calor humano (Giordano, 1997).

El carácter formal de "agrupación con fines culturales" no fue sin embargo un objetivo premeditado por parte de Mena ni de Boglietti, el objetivo inicial fue reunirse y pasar un buen rato entre amigos, y en ese sentido el Fogón no difería del Ateneo, cuya dinámica grupal se aproximaba a la de un club o una peña. Al respecto Hilda Torres Varela, una de las concurrentes a las primeras reuniones, comenta:
"Al principio, todos los martes, Aldo hacía hablar a alguien del pueblo, sobre algún tema de interés, y eso fue dando alguna continuidad, pero él nunca pensó que eso era actividad cultural, ni que estaba haciendo cultura. Esa era su forma de vivir. Lo mismo cuando se hacía teatro leído desde el '49 en el Fogón, era todo informal” (citado en Giordano, 1998).

Con el paso del tiempo El Fogón llegó a cobrar cada vez mayor relevancia cultural tanto en Resistencia, como en el resto de la provincia y del país. Esta difusión y conocimiento de su accionar -especialmente en el ámbito nacional- se vio favorecido por las diversas visitas de expositores y conferencistas que se acercaban a este peculiar ámbito calificándolo como "museo del disparate", "rincón de amigos" o "museo existencialista". De marcada tendencia cosmopolita, el Fogón comenzó a adquirir perfiles propios en el contexto de la modernidad chaqueña y a contraponerse a las otras agrupaciones surgidas anterior o paralelamente bajo una marcada orientación nativista. Tal es el caso de la Peña Nativa Martín Fierro que para ese mismo periodo también surge en Resistencia ${ }^{7}$.

Variadas fueron las actividades promovidas por El Fogón, y numerosos los artistas que por allí transitaron y que al hacerlo fueron depositando algunas de sus obras en calidad de agradecimiento por la invitación y el trato recibido. Entre tales obras se hallan las pinturas y grabados de artistas reconocidos nacional e internacionalmente: Butler, Castagnino, Cochet, Delhez, Berni, Spilimbergo, Forte, Badii, Audivert, Gómez Cornet, Soldi, Seoane, Pettoruti, Sergi, Venier, Grela, Barragán, Forner, Bonome y otros; esculturas de José Alonso, Arranz, Budini, Lorenzo, Fontana, Gerstein, Knopp, Marchese, Polacco, Paez Vilaró, San Luis Sassone, Vinci, Schenone, Mena y otros.

Todas estas "devoluciones" (pinturas, esculturas, grabados, murales, escritos, etc. y algunos que otros objetos insólitos como la gallina de los huevos de oro o

\footnotetext{
${ }^{7}$ Pese a este espíritu universalista El Fogón, muchos de los artistas nucleados allí tuvieron un marcado "localismo temático y gestual" que unió tanto a los artistas oriundos del Chaco como los radicados en él (Giordano, 2003). La figura del indio, el criollo, el inmigrante, las costumbres rurales y el paisaje de campo, serán las líneas temáticas predominantes en las obras de pintores, escultores, poetas, etc. (Romagnoli, 2003).
} 
las medias de Ariel Ramírez antes de hacerse famoso) fueron depositándose en las paredes, rincones, pasillos, patios, terrazas y techos de El Fogón transformándolo en un abigarrado espacio de arte en sí mismo ${ }^{8}$.

Por desconcierto, admiración o gracia, El Fogón iba afectando su espacio privado al uso público seduciendo a artistas, críticos, entusiastas del arte y público en general que asistían maravillados a una insólita integración entre obras de arte y objetos pop: frases en su mayoría humorísticas se entremezclaban en un "armónico desorden" con litografías de Pettoruti o los óleos de Vicente Forte. Integración que fue leída por Córdova Iturburu (1961) como una suerte de "equilibrio" convertido en "símbolo preciso de lo que humanamente es, por otra parte, el espíritu que anima a esta fraternidad de amigos que la puebla y presta su comunicativo calor de vida a esa casa donde se hacen cosas serias con aire risueño"9.

Tanto por las obras expuestas como por la dinámica y funcionamiento de sus integrantes, El Fogón fue un exponente de modernidad en Resistencia. También lo fue en el plano arquitectónico. El nuevo edificio fue encargado por Boglietti al arquitecto de origen santafesino Horacio Mascheroni, quien entre 1952 y 1955 se ocupó de dar forma a este inusual espacio acorde a la dinámica transgresora de quienes lo habitaban ${ }^{10}$.

Con una notoria adherencia a las ideas modernas, y en especial a las de Le Corbusier, Mascheroni construyó el nuevo edificio El Fogón en cuya conformación se advierte el uso del volumen cilíndrico, la alusión permanente a las formas geométricas puras, la reducción del uso del blanco, la articulación de volúmenes conectados entre sí a través de rampas y paredes onduladas, y en especial, una concepción de la arquitectura apoyada en la utilización del recorrido como recurso de trayecto, búsqueda y factor de sorpresa (Bernardi, 2002:29,30). Este dinamismo del espacio no sólo estuvo determinado por las rampas y ondulación de las paredes que se disparaban en mil direcciones, sino también por las múltiples imágenes, escritos y objetos adheridos a las paredes y descubiertos a medida que el visitante avanzaba (Bernardi: 2002:31).

Las paredes, escaleras y puertas pintadas por Capristo, Jonquières, Grela, Gorrochategui, Vázquez, Badii, Bonome, Arranz, Fernández Navarro y Brasco se complementan con los murales de Urruchúa en la sala principal (1954), los de Vanzo, Marchese y Monsegur en el patio (1955). Dentro y fuera y en las terrazas transformadas en jardines conviven las obras de Gerstein, Fontana, Pettoruti, Erzia, Páez Vilaró,

\footnotetext{
${ }^{8}$ La heterogeneidad de las obras de escultores, pintores, grabadores, dibujantes, poetas, etc. adheridas a la cotidianeidad del espacio El Fogón, junto a la peculiaridad de las actividades desarrolladas y la excentricidad de sus promotores provocó las más diversas descripciones El Fogón: museo, institución cultural, club, "caja de sorpresas", "templo de amistad", "estilo de vida", "modo de ser" (Giordano, 1999).

${ }^{9}$ Audición radial del 21 de julio de 1961. Radio Municipal, Buenos Aires. Archivo El Fogón de los Arrieros. En Romagnoli (2003).

${ }^{10} \mathrm{La}$ arquitectura argentina de los años ' 30 se desarrolló sobre los vectores de una nueva expresión estilística de influencia vanguardista europea. Mascheroni fue uno de los representantes del movimiento moderno local, en una época en la que hacer arquitectura suponía prácticamente empezar de cero y en la que una joven conciencia de ciudad en formación buscaba conformar su identidad (Bernardi, 2002:28,33).
} 
Soldi, Severini, Castagnino, Uriarte, Gambartes, Pucciarelli, Bigatti, Barragán. A ellas se suman las obras de artistas locales como Brusau, Castillo, Torre, Fernández (Torres Varela, 1979).

Entrada ya la década del '50, "el arte comienza a fluir de manera impensada en la Resistencia "fenicia" de la época" (Giordano, 1998:37) y esta fluidez se dará al interior de esta formación cultural. Si bien desde décadas pasadas comenzaron a surgir numerosos espacios privados que fueron afectados al uso público como bares, restaurantes, teatros, cines, clubes, etc. ninguno había logrado incorporar el arte como elemento aglutinador con el espacio interior de sus edificios, y en este sentido, El Fogón llevó la delantera (Giordano, 1998).

Fomentar la cultura regional y nacional desde la mirada europea, en esta línea podría resumirse el objetivo organizacional y estético El Fogón. Ámbito que para la década del '50 comienza a brindar un panorama del arte nacional. En una ciudad en pleno desarrollo económico y cultural, con poca inclinación al arte, este núcleo llegó a convertirse -en palabras de Giordano (1998:40)- en un "oasis cultural" para algunos que otros espíritus ávidos de belleza.

\section{Los '60 en Resistencia}

\section{2. a. Nuevos circuitos para el arte}

Intensos fueron los cambios y circunstancias que -en todos los campos de la actividad humana- marcaron el inicio de una nueva década en los años sesenta. Los proyectos artísticos elaborados desde la inmediata post-guerra comienzan a fusionarse con los surgidos como expresión de la cultura pop, los mass media, la publicidad, la industria, el consumo, etc. Se produce el encuentro New York - Paris y se atemperan las asperezas que habían enfrentado a los artistas de acción americanos con los informalistas europeos. Mientras que Europa presenta nuevas propuestas e intenta recuperar su olvidado prestigio, Estados Unidos afianza su imagen como cabecera artística.

Como en las grandes capitales artísticas europeas y estadounidenses, Argentina no escapa a la vorágine de renovaciones culturales, sociales y políticas de esta época. En el panorama cultural nacional los años sesenta estuvieron impregnados de grandes transformaciones sociales y profundas conmociones estéticas y políticas: a la sensación de un urgente y necesario giro político, se sumaron la expansión de los espacios de producción, la preminencia de la dimensión pública y mediática de las acciones culturales y la ruptura de los convencionales lenguajes estéticos ${ }^{11}$. Los

\footnotetext{
${ }^{11}$ La posición metropolitana de Buenos Aires, como capital del nuevo estado y nación modernos, será el punto desde el cual comenzarán a tejerse los discursos y acciones culturales revolucionarias. No obstante habrá ciudades que tendrán una intervención clave en el campo artístico argentino de los sesenta y que también serán polos activos de la década. La Plata (representada por el Grupo Sí-vinculado al informalismo, Eduardo Vigo -iniciador del conceptualismo, Alejandro Puente y César Parternosto renovadores de la pintura geométrica), Rosario (representada por la Galería Carrillo Artes Visuales, la
} 
productos culturales comenzaron a abandonar los tradicionales circuitos y formatos de exposición, aunque la actividad de los museos se dinamizó estimulando una mayor participación del espectador ${ }^{12}$.

Todos estos impulsos modernizadores de los años sesenta argentinos impactan en cierta medida en la escena cultural de Resistencia. El espíritu de época caracterizado por una fuerte necesidad de cambio y exploración de vías alternativas en la esfera del arte, se intuye en la capital provincial del Chaco, donde surgen nuevas maneras de concebir la difusión, promoción y circulación de las artes visuales.

Al impulso significativo brindado por las ya mencionadas iniciativas de $E l$ Fogón de los Arrieros en la década del cuarenta y cincuenta se suman ahora las acciones provenientes del ámbito oficial y privado. Entre las primeras se hallan las realizadas en el marco de la Dirección de Cultura, espacio institucional que ya había existido con anterioridad pero que no había sido ocupado sino hasta 1957 bajo la conducción de Hilda Torres Varela, figura de relevancia en el ambiente cultural e integrante del círculo de El Fogón de los Arrieros ${ }^{13}$.

En el ámbito institucional privado continúan la labor de difusión y promoción cultural del Ateneo del Chaco, que organiza entre 1960 y 1964 muestras con obras de artistas locales (Oscar Sánchez Kelly y Héctor Díaz) nacionales (Gorrochategui, Lasansky y Adela Tarraf) y quienes provenientes de otras provincias residen en Resistencia (Eddie Torre y Félix Barletta, entre otros).

Las exposiciones sin embargo no tienen lugar sólo en salas especialmente preparadas para ello, como el Salón de Actos del Consejo General de Educación, sino también en espacios poco convencionales como bares (Sorocabana), comercios (Casa Oligario, Cimat, edificio Olivetti) Cine Terraza Chaco, Salón de la Agencia local del Diario Clarín, asociaciones de inmigrantes como la Asociación Italiana, la Sociedad Española de Socorros Mutuos y la Alianza Francesa, Salón de Actos de la UNNE,

colección de Isidoro Slulliter y el Grupo de artistas de vanguardia), y Córdoba con los Salones IKA y la Bienal Americana de Arte organizada por las Industrias Kaiser en 1962, 1964 y 1966) (Pacheco, 2007).

${ }^{12}$ En este contexto el campo artístico argentino sufrirá importantes transformaciones y el accionar de varias instituciones que pasarán a ser agentes de legitimación será también fundamental. El Museo Nacional de Bellas Artes y el Museo de Arte Moderno de Buenos Aires son dos de las instituciones oficiales más influyentes. Sus sucesivos directores Jorge Romero Brest, Rafael Squirru y Hugo Parpagnoli fueron figuras que marcaron una impronta en la construcción de líneas teóricas y artísticas (Pacheco, 2007: 17). En el ámbito privado, el Instituto Torcuato Di Tella y su Centro de Artes Visuales dirigido por Jorge Romero Brest son también los centros más destacados y polémicos del periodo, con sus gestos de inclusión y exclusión del dominio consagrado del arte. Muestras de avanzada, implementación de una política de premios de alcance internacional, becas, conferencias, introducen nuevos modelos de gusto y amplían los márgenes establecidos en el campo de las artes plásticas (Giordano, 2003).

${ }^{13}$ Se crea por otro lado, la Academia Provincial de Bellas Artes -sobre la base de la Escuela de Dibujo y Pintura creada en 1954. Esta institución tendrá un vehemente desarrollo bajo la dirección del escultor Mauro Glorioso, en primera instancia, y por el arquitecto Francisco Dellamea, posteriormente. Desde la administración universitaria también se dará apoyo a la renovación de las artes plásticas. El Dr. Oberdan Caletti, decano de la Facultad de Humanidades de la UNNE crea en 1958 el Taller de Arte Regional bajo la organización y dirección del escultor Carlos Schenone. 
bibliotecas Rivadavia, Avellaneda y Herrera, la Pérgola de la Plaza central 25 de Mayo con su propuesta de una "comunicación abierta" del mensaje artístico ${ }^{14}$.

En la conformación de campo artístico de Resistencia en la década de los ' 60 también interviene la inauguración de la Sala de Actos Culturales (el 16 de julio de 1961), en la que se organiza la muestra colectiva de los plásticos ligados al Taller de Arte Regional (Eddie Torre, Lorenzo Ávalos, Oscar Sánchez Kelly, Juan Carlos Soto y Mariano Villegas), conocidos como Grupo Gualamba. El catálogo de la exposición presenta la producción de estos artistas como un "arte sin concesiones, proclive a los lenguajes modernos y desprovisto de academicismos". La presencia del critico Córdova Iturburu la noche de la inauguración y su alentadora devolución a los jóvenes artistas marca también un signo de legitimación para las artes plásticas regionales. Este hecho genera gran expectativa en muchos sectores de la sociedad que acuden a la exposición ${ }^{15}$.

En 1963 surge una nueva agrupación conformada por Eddie Torre, Oscar Sánchez Kelly y Rodolfo Schenone. Bajo el auspicio de la Dirección de Cultura, el Consejo de Educación, el Taller de Arte Regional y la Asociación de Residentes chaqueños en Capital Federal, los tres artistas exponen en la Casa del Chaco en Buenos Aires e inician un ciclo de actividades artísticas que pretendían mostrar el quehacer cultural chaqueño.

Los lenguajes plásticos renovadores surgidos en estas experiencias del grupo son el resultado de una nueva sensibilidad suscitada por profesores locales que conocían los nuevos lineamientos vanguardistas, tanto por sus viajes de estudio a otras provincias como Santa Fe, Córdoba o Buenos Aires en las que descubren las últimas expresiones de la plástica nacional y en algunas circunstancias las propuestas de artistas extranjeros cuyas obras eran expuestas en muestras internacionales.

También son importantes las influencias de grandes artistas que llegan a Resistencia en calidad de maestros invitados por el Ateneo del Chaco, El Fogón de los Arrieros y el Taller de Arte Regional de la UNNE. A esto se suma el manejo de información actualizada sobre la situación del arte en Argentina y en el exterior facilitada por la hemeroteca de la UNNE, el Instituto Di Tella y las diferentes embajadas de países europeos y americanos que difundían las últimas noticias culturales ${ }^{16}$.

\footnotetext{
${ }^{14}$ Este último espacio ya había sido en los años 40 uno de los puntos de enclave de obras de artistas locales. A partir de los 60 éste será el ámbito que convocará a los egresados de la Escuela de Bellas Artes de la Provincia y el Taller de Arte Regional de la UNNE. Estas experiencias entre el arte y el público de la plaza se proyectarán en 1988 con los concursos de esculturas que continúan vigentes hasta hoy.

${ }^{15}$ Pese a esta auspiciosa repercusión el grupo finalmente se disuelve. De algunos de sus integrantes (Oscar Sánchez y Juan Carlos Soto) junto a Enrique Gamarra y Jorge Gómez López surge el también efímero Grupo Arypo (Arte y poesía) que presenta poemas ilustrados en bares y bibliotecas.

${ }^{16}$ En cuanto a las diversas manifestaciones que desde el punto de vista formal abarcó el denominado arte nuevo: informalismo, arte conceptual, pop, arte de los objetos, videoarte, ambientaciones, happenings, instalaciones y arte de los medios, no encontraron su lugar en la capital chaqueña durante los ' 60 . Todas estas expresiones comienzan a vislumbrarse en los ' 80 y ' 90 . Recién entonces cobran vida las líneas planteadas décadas anteriores en Buenos Aires, Rosario y Córdoba y los ingenuos gestos vanguardistas atisbados en los '60 llegan definitivamente a quebrar el orden tradicional implantando nuevas reglas
} 
Otro de los signos vanguardistas de la década que se advierte en Resistencia, es el nuevo panorama de circuitos socio-artísticos, muchos de ellos no convencionales que apuntan a una difusión masiva del arte en contraposición con una experiencia estética elitista, accesible a una minoría especializada que hasta entonces frecuentaba el Ateneo del Chaco y El Fogón de los Arrieros. Esta necesidad de ampliar los horizontes de recepción se observa no obstante en el propósito del mismo Fogón de difundir el arte en el ámbito urbano y en la creación de las dos instituciones de enseñanza artísticas mencionadas que con sus acciones contribuyen a expandir los habituales canales comunicacionales del arte; canales hasta entonces fijos en sus reglas y funciones: la Academia Provincial de Bellas Artes y el Taller de Artes Visuales de la UNNE.

En el medio de este escenario local, en el que se viven importantes procesos de efervescencia intelectual y estética caracterizados por una marcada experimentación, el Fogón no estuvo ajeno y se propuso abrir un "museo ciudadano". Museo donde la obra de arte esté integrada al paisaje urbano.

"Sacar el arte a la calle", "exhibir bajo las estrellas", éstas fueron la premisas del Fogón que comenzaron a efectivizarse en manos de Aldo Boglietti (Giordano, 1997).

Hacia mediados la década del '60 El Fogón emplazará en el jardín delantero y en la vereda del edificio, un número importante de obras escultóricas. De esta forma comienza a integrarse el arte con la arquitectura y la vegetación: esculturas de artistas locales y de otras provincias se suman a la cotidianeidad del espacio público transformando el hasta entonces íntimo espacio del Fogón (en especial la vereda y hall exterior donde se realizaron los primeros emplazamientos) en un "nido escultórico" (Giordano, 1998:44). Paulatinamente El Fogón en su totalidad se convirtió en un espacio que cobijó a numerosas obras escultóricas, proponiendo desde un punto de vista paisajístico, una nueva modalidad de arte urbano y acercando el arte a una sociedad bastante alejada de las producciones culturales. Este acercamiento se hará más efectivo cuando El Fogón emprenda su plan de embellecimiento diseminando obras de arte en toda la ciudad ${ }^{17}$.

Esta actividad -que marcará el inicio de una transformación decisiva en la relación de los habitantes de Resistencia con el arte- consistió en el emplazamiento de cien esculturas en las veredas céntricas de la ciudad. Con esta acción no sólo la ciudad se transforma adquiriendo una nueva fisonomía, sino también la habitual experiencia de quienes la transitaban diariamente se modifica definitivamente (Gutiérrez Viñuales y Giordano, 1992).

La relación entre los actores sociales y el espacio urbano -históricamente condicionada por factores sociales, económicos y políticos -se complejizará de ahora en adelante con la intervención del arte en el ambiente público. Habrá quienes valorarán

para el arte (Pacheco, 2007: 24). Entre los representantes más destacados de esta nueva etapa del arte chaqueño se hallan Walter Tura, Diego Figueroa, Guillermo Locket, Dufva Nielsen, entre otros.

${ }^{17}$ Desde la metrópoli porteña el entonces director del Museo Nacional de Bellas Artes, Jorge Romero Brest apoyará la labor del Fogón, asesorando sobre la adquisición de obras, siendo el nexo entre el Fogón y los artistas y cediendo tres esculturas del Museo que aun hoy se hallan en las calles de Resistencia. 
los atributos estéticos de las obras, quienes por otro lado, las asumirán como bienes comunes que se integran a la vida cotidiana interactuando simbólicamente con ella y quienes simplemente serán indiferentes a su presencia. Pese a esta desigual reacción ante la presencia del arte en la ciudad, las esculturas adoptarán respectivamente un significado estético, social, comunicativo o funcional que se fusionará al paisaje, la edificación y los transeúntes proponiendo una nueva experiencia estética (Giordano, 1997).

\section{2. $b_{\text {i Vanguardia despolitizada? }}$}

$\mathrm{Si}$ bien los actores culturales chaqueños sintieron el impacto nacional e internacional de la década de los ' 60 , especialmente en la capital provincial, iniciando un proceso de cambio en su relación con las instituciones culturales, la enseñanza artística y la gestación de un nuevo tipo de artista, no estuvieron en completa sintonía con los grandes sucesos políticos que se desarrollaron en los otros puntos del país; puntos donde la modernidad artística encontró grados significativos de inflexión al vincularse estrechamente con la política.

Mientras que en Rosario o Buenos Aires se producía una creciente invasión de la política hacia todo el campo cultural, empujando a muchos artistas y formaciones culturales a enfrentarse con las instituciones, a trabajar por fuera de ellas, radicalizando las ideas políticas y marcando un punto crítico en la confluencia con la realidad del momento (Katzenstein, 2007:11), Resistencia se mantuvo al margen a este proceso.

Aunque existieron unas pocas manifestaciones vanguardistas en la coyuntura local, como la conformación y el desarrollo de El Fogón de los Arrieros, formación cultural en la que existió un proyecto de ruptura con la tradición, de negación de las convenciones estéticas y de experimentación con las formas de hacer y mostrar el arte, el quiebre con el discurso modernista se mantuvo en el plano meramente estético permaneciendo ajeno a la inminente politización que se vivió en otras provincias.

En éstas, la nueva situación política del país fue leída por un importante sector intelectual de la sociedad como el fin del aislamiento, la censura, el populismo. Esta lectura se convirtió rápidamente en convicción y luego en motor fundacional para apoyar acciones que prefiguraron el estatuto del denominado "arte nuevo". Tanto en Buenos Aires como en La Plata, Rosario y Córdoba, renació la sensación de un país liberado, sensación construida sobre la euforia de una acelerada implantación del modelo económico desarrollista y su slogan modernizador que comenzaba a desplegarse sobre la actividad cultural ${ }^{18}$.

${ }^{18}$ Inversiones extranjeras, particularmente norteamericanas, cambian la estructura de producción aportando un sentido económico relativamente constante. Artistas, críticos, instituciones oficiales y privadas, medios de comunicación serán los portavoces de esta eufórica aceleración de turbulencia política y desarrollo económico sostenido y diversificado. En el campo cultural esta "inyección" del capital se materializará en subsidios de fundaciones auspiciadas por industrias americanas (Ford y Rockefeller) y compañías multinacionales que estimulan financieramente las prácticas de vanguardia y su promoción internacional (Giordano, 2003). 
En Rosario los artistas llegaron al punto máximo de activismo artístico y político que reveló los límites de las vanguardias en su impulso transformador de la vida y la sociedad. Existió una concepción del arte que en palabras de Fantoni (1998:11) "involucraba la forma vanguardia como modificadora de la realidad". El arte era pensado en función de la noción de vanguardia, y la vanguardia como instancia de mediación con la política (Fantoni, 1998:15). La ruptura y la revolución eran una urgencia no sólo en el plano estético sino también en el ideológico, al punto tal que a la vanguardia estética debía corresponderle una actitud de vanguardia política. Ambos términos vanguardia estética y vanguardia política debían implicarse mutuamente ${ }^{19}$. Una no debía estar al servicio de la otra, sino por el contrario debía existir entre ambas lo que el artista Juan Pablo Renzi llamó "una confluencia dialéctica, creativa y creadora en una nueva situación formal. Situación que se daría a partir de la conjunción de la actitud de vanguardia, de indagación experimental, con la actitud ideológicamente revolucionaria" (Renzi, en Fantoni, 1998: 59).

Este rol socialmente importante que los artistas rosarinos otorgaron al arte, al querer fusionar dos lógicas que ante el sentido común aparecían como incompatibles: la vanguardia artística y la vanguardia política (Longoni, 1999: 158) no se dio plenamente en Resistencia ${ }^{20}$.

Si bien -tal como lo plantea la historiografía local- el influjo innovador de los sesenta se expresó en Resistencia especialmente en el replanteo institucional entre la obra de arte y el público; (replanteo que halló en el emplazamiento de esculturas y murales en la vía pública emprendido por El Fogón su máxima manifestación), no existió un movimiento vanguardista con sus ideales de ruptura en el plano político, aunque sí en el plano estético.

Pero ¿cómo entender el accionar cultural chaqueño de la década del ' 60 en términos de vanguardia, trasgresión o ruptura si tal accionar no estuvo precedido ni mediado por una fuerte tradición artística a la cual enfrentarse? ¿En qué medida hubo lugar para la relación (estrecha y necesaria) que una vanguardia debe experimentar con "el prestigio y la consolidación de una tradición y con las dimensiones del espacio cultural, cuya legalidad los nuevos actores van a poner en cuestión?" (Fantoni, 1994:182).

\footnotetext{
${ }^{19}$ La ideología que servía de plataforma política revolucionaria a los grupos vanguardistas de Rosario fue generalmente el marxismo concurrente con ciertas situaciones como las del mayo francés o la Revolución cubana (Fantoni, 1998:57).

${ }^{20}$ Un caso interesante y particular en este contexto es el del artista Clement Moreau de manifiesta adherencia al socialismo. Nacido en Coblenza, Alemania en 1903, llega a Buenos Aires en 1935 como exiliado político, incorporándose a la vida cultural chaqueña a fines de la década del ' 50 . Hasta 1962 reside en Resistencia y se desempeña como maestro de grabado en la Academia de Bellas Artes, en la que transmite su concepción del arte como canal eficaz para la comunicación con la sociedad. Si bien es reconocido como uno de los representantes destacados del arte antifascista alemán en el exilio y del "arte de crítica" en la Argentina, su obra no llegó a cobrar en Resistencia la magnitud de un "arte de denuncia". Pese a su gran activismo político en la ciudad no llegó a conjugar en una sola vía expresiva el arte con la ideología que defendía (Romagnoli, 1998).
} 
Como lo vimos anteriormente la conformación del campo artístico en Resistencia fue un proceso complejo en el que diversos factores (sociales, económicos y políticos) determinaron una gestación "lenta" respecto de las grandes metrópolis culturales del país. En tanto periférica la cultura chaqueña vivió al margen de muchos de los sucesos culturales acontecidos en las grandes ciudades, donde para la década del '60 ya existía cierta tradición artística consolidada. De modo que para esta misma época, el campo cultural local se hallaba en un proceso de plena sedimentación y decantación.

Si bien no contaba con una práctica artística arraigada en el campo cultural, Resistencia no estuvo completamente desvinculada de las profundas crisis políticas que inevitablemente afectaban a todo el país. Sin embargo los artistas e intelectuales no fusionaron el experimentalismo estético con el radicalismo político que caracterizó a los movimientos vanguardistas en otros puntos del país. Las innovaciones planteadas estuvieron reducidas al plano de la comunicación artística (la obra de arte y su recepción) fuera de los ámbitos convencionales.

Estas innovaciones propusieron nuevos espacios para la práctica artística borrando el límite entre el arte y el ámbito público, pero no se conjugaron con los procesos políticos de uno de los periodos más efervescentes del arte argentino. En Resistencia no existió entonces un arte "comprometido y confrontado" con la realidad social y política de la década. La inmersión del arte en la vida consistió exclusivamente en la trasgresión de los habituales canales de circulación artística. De modo que el contacto arte-sociedad, no tuvo como correlación inmediata el proceso de politización experimentado por ejemplo en Rosario o Buenos Aires.

Ello quizás obedezca al hecho de que la modernidad adoptó en la Argentina diferentes formas y las denominadas vanguardias siguieron distintas líneas de fuerza en distintos puntos del país; hubo algunas que se consustanciaron con la realidad política del momento y hubo otras que se concentraron en una preocupación meramente estética, como creemos fue el caso chaqueño.

Por ende, al momento de abordar la modernidad en Resistencia debiéramos tal como lo sugiere Huyssen (2006) distinguir las diferencias tanto históricas como políticas que intervienen en la noción misma de modernidad. Pese a que el marco temporal que suele aplicarse al modernismo internacional en las artes es uno solo (aquel que va desde fines del siglo XIX hasta mediados del siglo XX), la modernidad nunca fue experimentada igualmente en todos los espacios. La modernidad (en nuestro caso argentina) no fue un fenómeno general, ésta asumió características locales específicas en cada región del país.

De esta forma, siguiendo a Huyssen (2006), existieron importantes variantes temporales, espaciales y organizacionales dentro del marco desde el cual se fijó la modernidad argentina. Así como la transición fue el estado propio de la modernidad en tanto experiencia histórica, también lo fue en tanto manifestación de valores, visiones y representaciones de esa experiencia. Más que fenómenos generalizadores y 
generalizantes, las modernidades en Argentina fueron múltiples y recorrieron diversas trayectorias y coyunturas.

Asumir este planteo tal vez nos ayude a comprender aquellas "modernidades periféricas" propias de regiones no centrales como lo es la región chaqueña. Su desarrollo alternativo de la modernidad metropolitana, su variedad temporal y espacial en la experiencia de "lo moderno", da cuenta no sólo de un funcionamiento no simultáneo con otros espacios del país, sino también de un modo particular - entre otros posibles- de traducción, apropiación y por qué no, de "imitación" de la modernidad metropolitana y nacional.

Ello nos revela que el vanguardismo (en tanto cultura de la modernidad social y económica de la sociedad burguesa), tal como fue concebido en Europa o en los grandes centros urbanos de la Argentina como Buenos Aires, La Plata, Córdoba y Rosario, no pudo aplicarse ni interpretarse igualmente en otros espacios. Dicho en términos de Huyssen (2005:259) el modernismo y la vanguardia estuvieron siempre estrechamente ligados a la modernización social e industrial de determinado espacio cultural. ¿Cómo pensar entonces en una modernidad resistenciana, sin una modernización previa o conjunta?

En el Chaco los procesos de modernización (regidos por el progreso y adelanto tecnológico, científico y la industrialización sólida y extendida) que quizás tuvieron lugar en Buenos Aires, Rosario o Córdoba, no se efectivizaron en la década del ' 60 .

Por ello, no podemos volver a leer la historia de la modernidad artística-como ya lo sugirió Huyssen en los '80- unilateral y unidireccionalmente, no podemos seguir pensándolo como desarrollo lógico encaminado hacia una meta imaginaria. Grietas y fisuras se imponen en la experiencia de la modernidad en espacios y contextos particulares donde -atravesadas por variadas, disímiles y en ocasiones contradictoras modernizaciones- las prácticas culturales y artísticas se dispersan en distintas direcciones.

Es en este sentido que -en palabras de Casullo (2005:35) - el vanguardismo estético toma conciencia de que la modernidad es una "diáspora de modernidades que se deshacen en el aire, de tiempos distintos en lo social y en el alma que serán definitivamente inabarcables".

Así como en Argentina fue imposible una vanguardia homóloga a la europea, también lo fue en Resistencia respecto de la de Buenos Aires, Rosario o Córdoba. En el Chaco los artistas no se replantearon su lugar en la sociedad y en el contexto político que atravesaba el país, no sintieron la necesidad de redefinir su posición, como sí ocurrió en las vanguardias del resto del país. Pero para el ambiente cultural chaqueño estos "intentos vanguardistas" fueron oportunos. Las experiencias vividas si bien no fueron radicales, fueron al menos las adecuadas para la realidad y el clima de renovación propio de la atmósfera social, económica y cultural chaqueña, o dicho de otro modo, fueron las que respondieron a una de sus instancias de modernización. 
¿Qué aspectos de la realidad chaqueña resultaban entonces particulares en el contexto general del país para impulsar una visión diferente de la función del arte? En principio la fuerte tradición cultural de tendencia folclorista y nativista que contribuyó a dar un sello localista al desarrollo cultural de la provincia, joven por cierto en relación de otras de la República Argentina. Fundada en 1878 como colonia agrícola militar, dio inicio al proceso de ocupación formal por parte del Estado Nacional Argentino al entonces denominado Territorio Nacional del Chaco, provincializándose recién en 1951 (Leoni, 1996).

Esta situación agravó aún más su condición periférica o descentrada respecto del contexto nacional, demorando su desarrollo institucional, la conformación de un campo artístico autónomo y el afianzamiento político, social, tecnológico e industrial; lo que confluyó en la formación de una sociedad con sentido de modernidad y progreso singulares, aplicables a grupos o sectores minoritarios.

El espíritu moderno se expresó en ciertos artistas -como los que se nuclearon incluso en torno de El Fogón de los Arrieros- en un marcado "localismo temático y gestual" (Romagnoli, 2003) a través de la figura del indio, el criollo, el inmigrante, las costumbres rurales y el paisaje de campo. Estas líneas temáticas predominantes en las obras de varios pintores, escultores, poetas, etc. convivieron en permanente tensión con aquella tendencia universalista del propio Fogón, ya que la intención era hacer un arte con sentido regional pero con una inserción plena en el mundo (Romagnoli, 2003). El sentido regional no buscaba el pintorequismo fácil sino que trataba de mostrar la realidad chaqueña con un lenguaje "moderno y universal" (Giordano, 2003) y este rasgo es justamente una de las peculiaridades del campo artístico chaqueño, en consonancia con la incipiente modernización industrial, técnica y sociopolítica de la ciudad y la provincia.

No obstante, si atendemos a la situación política institucional argentina, el Chaco estuvo marcado en los años 60 por una compleja sucesión de gobiernos constitucionales e intervenciones militares. Sin embargo, y pese a que el clima sociopolítico era similar al que despertó en otras ciudades la fuerte reacción de artistas e intelectuales y marcó el rumbo hacia una inminente politización del arte, en Resistencia no se vivió la misma eclosión política en relación a la práctica artística ${ }^{21}$.

${ }^{21}$ En las elecciones del 18 de marzo de 1962 triunfó la Unión Cívia Radical Intransigente (UCRI) en Capital Federal y en diez provincias. En Chaco, donde resultó electa la fórmula Deolindo Felipe Bittel - Mario Ramón Villalba, de la Unión Popular, nombre usado por el partido peronista. Frente a tales resultados las Fuerzas Armadas exigieron que decretara la Intervención de las provincias donde había ganado el peronismo (Buenos Aires, Chaco, Río Negro, Santiago del Estero y Tucumán). El 19 de marzo cuando sólo faltaba un mes y doce días para culminar su mandato constitucional, el gobernador Duca entregó el gobierno de la provincia al interventor federal interino coronel Miguel Momm. El mismo, clausuró los locales de los partidos comunista y peronista, prohibió la realización de actos públicos y gremiales, intervino el Consejo General de Educación, el Instituto de Previsión Social y la Dirección de Tierras, Colonización Bosques, la Dirección de Vialidad Provincial y la Casa del Chaco en Buenos Aires. Entre junio y octubre de 1963 fue designado interventor Marcelino Castelán. Después de un largo proceso eleccionario, llega nuevamente al gobierno Deolindo Felipe Bittel después de haber evitado la 
Por ello, es importante subrayar que no fue condición necesaria de las vanguardias tener un rol en la lucha política, por lo que la ausencia de una acción política susceptible de desarrollarse a la par de un experimentalismo estético en Resistencia, no debiera leerse como una falta o carencia, en relación a otras ciudades, sino como parte de una contingencia que afectó en el caso chaqueño específicamente al terreno artístico.

Repensar el vínculo entre centro-periferia desde otros parámetros de emisión y difusión como los adoptados por El Fogón de los Arrieros, no implica por lo tanto, desconocer el surgimiento de las tendencias vanguardistas politizadas en las grandes urbes argentinas y por tanto, en contextos y condiciones de producción, circulación y recepción de productos artísticos, (y de relaciones entre el poder político, económico y cultural) distintos a las transitados en Resistencia hacia la década del ‘60.

\section{Consideraciones finales}

Durante las décadas que van de 1940 a 1960 el Chaco cuenta con iniciativas grupales próximas a la experimentación bohemia e indiferente respecto de cuestiones político-sociales en el campo cultural. En medio de una sociedad e intelectualidad en gestación, las formaciones culturales tuvieron una presencia plena, pero no tuvieron mayor participación en conflictos sociales y políticos.

No obstante, en esta etapa del arte chaqueño, las diferentes formaciones culturales -y en especial El Fogón de los Arrieros-cooperaron de manera substancial en la conformación de nuevas esferas culturales en las que se concretaron emprendimientos determinantes para la historia del arte regional (Romagnoli, 2003).

Tras un complejo proceso de autonomización y diferenciación, es recién en la década del '60 cuando llega a conformarse y legitimarse un campo artístico chaqueño; campo cuyos actores y agentes relacionándose mutuamente y refiriéndose recíprocamente, se desafiaron para lograr instancias específicas de selección y consagración propiamente artísticas en el contexto social, económico y político de la provincia.

proscripción que pesaba su partido, merced a un acuerdo con el Partido Conservador del Chaco. Para las elecciones 1965 se levantaron tales proscripciones y en junio de 1966 cuando se llevó a cabo el Golpe de Estado (por medio del cual los comandantes en jefe de las tres armas formaron una junta revolucionara que destituyó al presidente, el vicepresidente, los miembros de la Suprema Corte, los gobernadores e intendentes electos, el Congreso, las legislaturas provinciales y los partidos políticos, designando a Juan Carlos Onagnía como Presidente de la República) llega al gobierno del Chaco, Ricardo Pacífico del Corazón de Pompeya Miró. Le siguieron en su cargo Rafael Torrado (1966-1997), Miguel Ángel Basail (1967-1971), Roberto Mazza (1971-1973). Producidas las elecciones del 11 de marzo de 1973 en todo el país, el Frente Justicialista de la liberación permitió la llegada al poder de Héctor Cámpora. En el Chaco el triunfo del Justicialismo llevó a la gobernación a Deolindo Bittel. Con el Golpe de Estado de 1976 a cargo de Videla, Massera y Agosti, asume como interventor en el Chao, el coronel José Zucconi y lo suceden Antonio Serrano y José Ruiz Palacios, hasta que en 1983 con el restablecimiento del orden constitucional asume como gobernador Florencio Tenev y como vicegobernador Alberto Torresagasti (Beck, 1996). 
El campo artístico chaqueño fue entonces el resultado de un desarrollo interno dentro del campo cultural resistenciano, pero también el producto de un desarrollo más general en la organización de Resistencia, en sus modos particulares de producción simbólica, económica y cultural.

Entrada la segunda mitad del siglo XX, hacia la década del '60, El Fogón de los Arrieros elegirá organizarse bajo la modalidad no de una afiliación formal, sino alrededor de una presencia colectiva pública, cuya manifestación más explicita será la concreción del plan de embellecimiento de la ciudad con el emplazamiento de esculturas. Lo interesante de esta agrupación es que además de conformar un programa alrededor del cual se nuclearon sus integrantes, definió una posición social más general respecto de los otros grupos al suscitar diversas opiniones acerca del "valor social del arte", opiniones que en ocasiones se enquistaron en posiciones ideológicas enfrentadas. De modo que esta agrupación además de congregarse por la filiación de sus miembros logró una identidad pública relevante, sea por la aceptación e identificación como por el rechazo o la indiferencia social.

Todas o casi todas las manifestaciones artísticas chaqueñas de las décadas del ' 60 estuvieron plenamente integradas al accionar del Fogón y -siguiendo a Fantoni (1994)- legitimadas por una política de premios y salones, mecanismos del mercado artístico y un público creciente.

Para concluir, cabe expresar que las formaciones de tipo moderno se originan en Resistencia en momentos de transición y de intersección dentro de una historia social compleja del Chaco. Entre cada una de las formas de organización cultural analizadas, existe una relación directa, cuyo orden se integra al orden social general de la ciudad de Resistencia en un momento específico de su historia.

Llegados a este punto, y tras el intento de descripción y análisis de las condiciones sociales que incidieron en el complejo proceso de conformación y legitimación cultural del arte chaqueño, podemos afirmar que todo lo que el análisis formacional del periodo comprendido entre 1940 y 1960 puede hacer, es plantear nuevos interrogantes sobre la historia del arte regional, sugerir dentro del estudio del arte chaqueño otras áreas más específicas de análisis, como por ejemplo aquella focalizada en la relación arte y política.

Sin adentrarnos en el análisis exhaustivo del accionar de cada una de estas formaciones, como así tampoco en el examen de las producciones artísticas del periodo, intentamos rastrear y exponer algunas de las circunstancias sociohistóricas que comprendió el complejo proceso de conformación del campo artístico chaqueño, identificando a ciertas figuras y explicando algunas de sus intervenciones, para reflexionar sobre las experiencias culturales y las renovaciones estéticas del arte de Resistencia entre 1940 y 1960. Por tal motivo hicimos hincapié en aquellas instancias específicas de la vida cultural chaqueña en las que a la vez que se seleccionaron y consagraron formas propiamente artísticas, se multiplicaron y diferenciaron éstas de otras formas de consagración social, se amplió el público capaz de consumir arte y éste 
último se integró como sistema cada vez más independiente de influencias externas atendiendo exclusivamente a las exigencias de lo que Bourdieu denomina "proyecto creador".

Sin caer en el relativismo extremo de remarcar únicamente las oposiciones y contradicciones, es importante resaltar también la complejidad particular del campo artístico chaqueño en función de las concordancias y afinidades posibilitadas por un clima de época compartido a nivel nacional e internacional (Longoni, 2006). Dicho en términos de Wechsler (2005) se hace preciso reescribir la historia del arte moderno en la Argentina de modo mucho más dialéctico, reconociendo sus tensiones y conflictos tanto al interior del espacio artístico como en la relación entre éste y la sociedad local y nacional. Ello abre la discusión acerca de la posibilidad de promoción de un campo artístico con cierta autonomía para la ciudad de Resistencia a partir de los centros de producción artística, y revela la consideración de nuevos matices para el tratamiento un tema complejo y denso de la historia del arte argentino.

\section{Referencias bibliográficas}

Anderson, Perry. 2004 “Modernidad y Revolución”. En Casullo, Nicolás (Comp.) El debate Modernidad-Posmodernidad. $2^{\circ}$ edición ampliada. Buenos Aires, Retórica, , pp.107-125.

Beck, Hugo. 1996 “Gobierno de la Intervención Federal (1955-1958)”. En Nordeste N². Serie Investigación y Ensayos. Resistencia, Facultad de Humanidades, Universidad Nacional del Nordeste, pp. 95-100.

. 1996. "Gobierno de Anselmo Zoilo Duca (1958-1962)". En Nordeste No 2. Serie Investigación y Ensayos. Resistencia, Facultad de Humanidades, Universidad Nacional del Nordeste, pp. 101-106.

. 1996. "Gobierno de la Intervención Federal (1962-1963)". En Nordeste No 2. Serie Investigación y Ensayos. Resistencia, Facultad de Humanidades, Universidad Nacional del Nordeste, pp. 107-112.

. 1996. "Gobierno de Deolindo Felipe Bittel (1963-1966)". En Nordeste No 2. Serie Investigación y Ensayos. Resistencia, Facultad de Humanidades, Universidad Nacional del Nordeste, pp.113-127.

Bernardi, Marcela. 2002. "Lo moderno en Resistencia. El edificio del Fogón de los Arrieros”. En Negrete Sánchez Ángela (Dir.) Cuadernos del CEHAU (Centro de estudios históricos, arquitectónicos y urbanos) - NEA. Resistencia, Facultad de Arquitectura y Urbanismo Universidad Nacional del Nordeste (UNNE), pp. 27-34.

Bourdieu, Pierre. 2003. Campo de poder, campo intelectual. Itinerario de un concepto. Buenos Aires, Editorial Quadrata.

Canclini García, Néstor. 1995. Culturas híbridas. Estrategias para entrar y salir de la modernidad. Buenos Aires, Sudamericana.

Casullo, Nicolás. 2005. "Modernidad. Biografía del ensueño y la crisis (introducción a un tema). En El debate Modernidad-Posmodernidad. $2^{\circ}$ edición ampliada. Buenos Aires, Retórica, pp.175-52.

Fantoni, Guillermo. 1998. Arte, vanguardia y política en los años '60. Conversaciones con Juan Pablo Renzi. Buenos Aires, El Cielo por Asalto.

1994. "Rupturas en perspectiva: Modernismo y vanguardia en el arte de Rosario". En Cuadernos del CIESAL, CEI/UNR, año 2, nº 2/3, $1^{\circ}$ y $2^{\circ}$ semestre, pp. 177-184. 
Reyero. El fogón de los arrieros ¿Una vanguardia despolitizada?

Giordano, Mariana. 2007. "Exhibir bajo las estrellas. Un Museo al aire libre". En Bellido Gant, María Luisa (Coord.) Aprendiendo de Latinoamérica. El Museo Como protagonista. Asturias, Ed. Trea, Gijón, pp.127-144.

. 2003. "La consolidación del campo artístico chaqueño (1960-1990)." En 50 años de arte chaqueño. 1953-2003. De los pioneros a los nuevos lenguajes. Resistencia, UNNE - Centro Cultural Nordeste. pp. 21-29.

. 1999. Juan de Dios Mena. Buenos Aires, CEDODAL. (Centro de Documentación de Arte y Arquitectura Latinoamericana).

. 1998. Los murales chaqueños. Del Fogón de los Arrieros a la Plaza 25 de Mayo de Resistencia. Cuadernos de Geohistoria Regional No 34 - Resistencia, Instituto de Investigaciones Geohistóricas (IIGHI), 105 pp.

. 1997. Historia de la Formación de una Simbología Urbana. Arte y espacio público en Resistencia. Resumen extendido. Segunda Reunión de Comunicaciones Científicas y Tecnológicas. Corrientes, UNNE. Actas Tomo I.

Gutiérrez Viñuales, Rodrigo y Giordano, Mariana. 1992. "El Fogón de los Arrieros y el plan de embellecimiento de Resistencia durante la década del sesenta". Resistencia, Instituto de Investigaciones Geohistóricas, pp. 161- 175.

Huyssen, Andreas. 2006. "Geografías del modernismo en un mundo globalizado". Traducción: Mirta Rosenberg En Modernismo y globalización. Nota periodística. Diario La Nación. Publicada el domingo 20 de agosto de 2006 | Disponible en URL:http://www.lanacion. com.ar/edicionimpresa/suplementos/cultura/nota.asp?nota_id=832798. . 2005. "Guía del posmodernismo". En Casullo, Nicolás (Comp.) El debate ModernidadPosmodernidad. $2^{\circ}$ edición ampliada. Buenos Aires, Retórica, pp.229-268.

Katzenstein, Inés. 2007. Escritos de vanguardia. Arte argentino de los '60 (Introducción). Buenos Aires, Fundación Espigas, pp. 8-13.

Leoni, María Silvia. 1996. "El primer gobierno constitucional del Chaco". En Nordeste $\mathrm{N}^{\circ}$ 2. Serie Investigación y Ensayos. Resistencia, Facultad de Humanidades, Universidad Nacional del Nordeste, pp. 93-100.

Longoni, Ana. 2006. "el deshabituador. Ricardo Carreira en los inicios del conceptualismo". En Arte y Literatura del siglo XX. Buenos Aires, Fundación Espigas. . 1999. "El pasaje a la política". En Eduardo Favario: entre la pintura y la acción. Obras 1962-1968, en co-autoría con Graciela Carnevale y Guillermo Fantoni. Rosario, Centro Cultural Parque España.

Pacheco, Marcelo. 2007. "De lo moderno a lo contemporáneo. Tránsitos del arte argentino 19581965”. En Escritos de vanguardia. Arte argentino de los '60. Buenos Aires, Fundación Espigas, pp.16-27.

Romagnoli, Miryam. 2003. "Forjadores de sueños: los pioneros del arte chaqueño". En 50 años de arte chaqueño. 1953-2003. De los pioneros a los nuevos lenguajes. Resistencia, Centro Cultural Nordeste - Universidad Nacional del Nordeste (UNNE), pp. 11-20. . 1998. "Una artista alemán en el Chaco. El otro rostro de Clement Moreau". En Actas del XVIII Encuentro de Geohistoria Regional. Resistencia, Chaco, Instituto de Investigaciones Geohistóricas del CONICET, pp.429-440.

Torres Varela, Hilda. 1979. "El Fogón”. En El Chaco y su cultura. Esculturas I. Buenos Aires, Inca.

Wechsler, Diana. 2005. "Hacia la delimitación de una crítica sociológica en la Argentina". En Giunta, Andrea y Malosetti Costa, Laura (comp.) Arte de posguerra. Jorge Romero Brest y la revista Ver y Estimar. Buenos Aires, Paidós, pp221-242.

Williamas, Raymond. 2000. Marxismo y Literatura. Ediciones Península, Barcelona. 1994. Sociología de la Cultura. Barcelona, Paidós. 